\title{
Author Correction: Lipid-droplet-accumulating microglia represent a dysfunctional and proinflammatory state in the aging brain
}

Julia Marschallinger, Tal Iram, Macy Zardeneta, Song E. Lee, Benoit Lehallier (1), Michael S. Haney, John V. Pluvinage, Vidhu Mathur, Oliver Hahn, David W. Morgens, Justin Kim, Julia Tevini, Thomas K. Felder (1D, Heimo Wolinski,

Carolyn R. Bertozzi, Michael C. Bassik, Ludwig Aigner and Tony Wyss-Coray (i)

Correction to: Nature Neuroscience https://doi.org/10.1038/s41593-019-0566-1, published online 20 January 2020.

In the version of this article initially published online, the top left and bottom right panels in Fig. $4 \mathrm{~h}$ were accidentally duplicated. Additionally, in the section "CRISPR-Cas9 screen identifies genes linked to neurodegeneration as genetic regulators of lipid droplet formation", the second sentence of the third paragraph should read, "We found 112 genes that were significant positive or negative regulators of lipid droplet formation $(P<0.05$; false discovery rate $(\mathrm{FDR})<5 \%)$ (Fig. 6e)." The errors have been corrected in the print, PDF and HTML versions of this article.
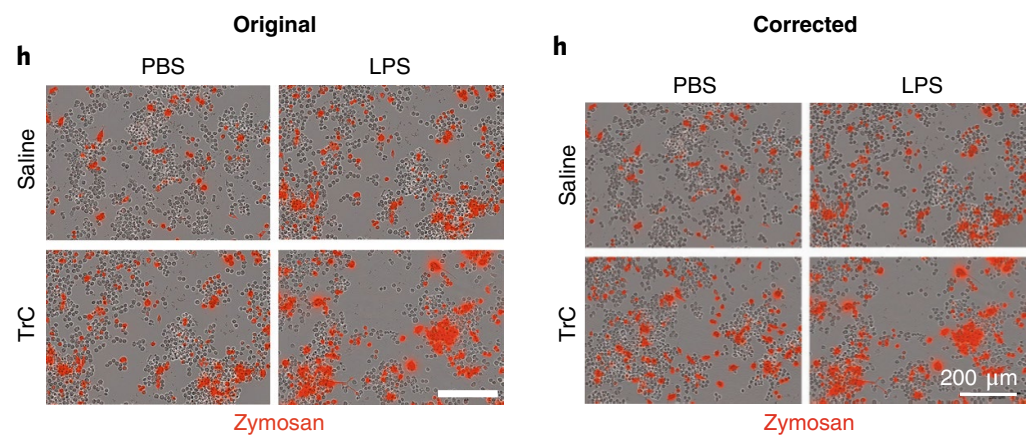

Fig. 4 | Original and Corrected.

Published online: 31 January 2020

https://doi.org/10.1038/s41593-020-0595-9

(c) The Author(s), under exclusive licence to Springer Nature America, Inc. 2020 